\title{
Os Testudines continentais do Rio Grande do Sul, Brasil: taxonomia, história natural e conservação
}

\author{
Clóvis S. Bujes ${ }^{1,2}$ \\ 1. Programa de Pós-Graduação em Biologia Animal, Departamento de Zoologia, Instituto de Biociências, Universidade Federal do Rio \\ Grande do Sul. Av. Bento Gonçalves, 9500, Prédio 43435, Sala 105, 91509-900, Porto Alegre, RS, Brasil. (clovis.bujes@ufrgs.br) \\ 2. ONG Projeto Chelonia: Biologia, Manejo e Conservação de Anfíbios e Répteis. (projetochelonia@gmail.com)
}

\begin{abstract}
Freshwater turtles of Rio Grande do Sul, Brazil: taxonomy, natural history and conservation. Rio Grande do Sul is the southernmost state of Brazil with peculiar flora and fauna associated to the morfoclimatic characteristics of the region. The diversity of Testudines from Rio Grande do Sul is represented by six freshwater turtle species and five sea turtle species. This study reports on the freshwater turtle diversity of Rio Grande do Sul, based on a compilation of published and some new data on their biology and conservation status.
\end{abstract}

KEYWORDS. Acanthochelys, Hydromedusa, Phrynops, Trachemys, freshwater turtles.

RESUMO. O Rio Grande do Sul é o estado mais meridional do Brasil, apresentando fauna e flora peculiares associadas às características morfoclimáticas da região. A diversidade de Testudines do Rio Grande do Sul é representada por seis espécies continentais e cinco marinhas. Este estudo apresenta comentários sobre a diversidade de quelônios continentais do Rio Grande do Sul, através de uma compilação de dados publicados e alguns inéditos sobre sua biologia e estado de conservação.

PALAVRAS-CHAVE. Acanthochelys, Hydromedusa, Phrynops, Trachemys, quelônios.

O domínio geográfico do Rio Grande do Sul corresponde à área mais meridional do Brasil, compondo a Região Sul com os estados do Paraná e de Santa Catarina. O território "gaúcho" possui características diferenciadas às demais áreas do país, principalmente se considerarmos o condicionamento morfoclimático responsável por certa tipologia de arranjos estruturais. Possui superfície de $282.184 \mathrm{~km}^{2}$; desse total, $14.656 \mathrm{~km}^{2}$ correspondem às grandes lagunas e ambientes lacustres interiores. A área rio-grandense representa 3,32\% da extensão territorial brasileira e as unidades morfoestruturais do relevo tornam o espaço totalmente ocupado pelo homem (VIEIRA, 1984).

O conhecimento sobre a história natural dos Testudines brasileiros é ainda rudimentar, apesar da sua grande diversidade (SouZA, 2004). As principais causas dessa carência de informações são atribuídas, principalmente, à dificuldade de obtenção de dados de animais na natureza (Moline, 1996), ainda que muitas espécies demonstrem certa elasticidade e convivam ou adaptam-se a ambientes antropizados.

A composição da fauna de répteis do Rio Grande do Sul é relativamente bem conhecida e, atualmente, são registradas 126 espécies para os limites territoriais do estado: 114 de Squamata (cinco cobras-de-duas-cabeças, 23 lagartos e 86 serpentes), uma de Crocodylia e 11 de Testudines (BENCKE et al., 2009).

No estado, Testudines ou quelônios são representados por seis espécies continentais (cinco de Chelidae e uma de Emydidae) e cinco marinhas (quatro Cheloniidae e uma Dermochelyidae), correspondendo a cerca de 30\% das 36 espécies brasileiras (BÉRNILS, 2010). No entanto, os estudos existentes sobre os quelônios continentais do Rio Grande do Sul são provenientes de informações pontuais temporal e geograficamente, que contribuem para a composição de um mosaico sobre a história de vida e o estado de conservação desses répteis.

Objetiva-se apresentar uma síntese sobre a diversidade de quelônios continentais, através de um inventário na literatura sobre aspectos da história natural e conservação das espécies em vida livre. Para tanto, foram utilizadas informações disponíveis em artigos científicos, trabalhos de conclusão de curso, dissertações de mestrado e teses de doutorado. A exemplo de SouzA (2004), comunicações referentes a encontros regionais, seminários, simpósios, congressos ou relatórios internos e técnicos, a chamada gray literature, não foram consideradas, uma vez que trabalhos dessa natureza carecem de avaliação de mérito ou averiguações minuciosas e criteriosas. Foram excluídos do inventário estudos de cunho laboratoriais (e.g. anatomia, fisiologia) e de cativeiro (e.g. comportamento, desenvolvimento), simplesmente por fugir ao objetivo desta publicação. As informações sobre hábitat e ecologia, parâmetros populacionais, ameaças à sobrevivência, medidas efetivas e propostas à conservação, reprodução em cativeiro e investigações atuais são, exclusivamente, de estudos realizados no Rio Grande do Sul. Para padronização de nomes de espécies, autores, sinonímias e observações taxonômicas seguiu-se Fritz \& Havas (2007). Como modelo para os subtítulos utilizou-se o proposto nas publicações da Conservation Biology of Freshwater Turtles and Tortoises (veja SouZa \& MARTins, 2009).

\section{Testudines}

Os amniotas, que incluem os Testudines, são classificados conforme a presença e o número de aberturas 
temporais no crânio. A condição Sinapsida (uma única abertura temporal) é verificada nos mamíferos e nos seus ancestrais reptilianos. A condição Diapsida (duas aberturas temporais) abrange a maioria dos reptilianos fósseis, bem como os atuais Archosauria (crocodilianos e aves) e os Lepidosauria (serpentes, lagartos, tuataras e anfisbenas). A condição Anapsida (ausência de aberturas temporais) engloba os quelônios e diversos grupos do paleozóico e do mesozóico (RoMER, 1966; BENTON, 1997). Porém, a posição dos quelônios entre os amniotas permanece um dos mais controversos temas. Atualmente são discutidas três hipóteses viáveis: (1) os quelônios como grupo-irmão do clado Archosauria; (2) como grupoirmão do clado Lepidosauria; ou (3) os quelônios na condição Diapsida (como um clado consequente das hipóteses 1 e 2). A primeira hipótese é apoiada por análises moleculares, enquanto as demais derivam de estudos morfológicos que incluem uma vasta gama de fósseis (LysOn et al., 2010).

Os quelônios formam um grupo monofilético que compreende a ordem Testudines ou Chelonia. Existem divergências quanto à terminologia comum usada para os vários grupos de quelônios. No idioma inglês, o termo tortoise refere-se às espécies terrestres que têm cascos altamente convexos e as patas colunares. O termo terrapin é usado para os quelônios dulciaquícolas, embora os britânicos usem o termo pond turtles para estas espécies. As espécies marinhas são referidas como sea turtles ou turtles. No Brasil, os representantes terrestres, dulciaquícolas e marinhos são conhecidos, respectivamente, pelos termos jabuti, cágado e tartaruga (HickMAN et al., 2004). Os quelônios são encontrados em todos os continentes, excetuando-se a Antártica, e em todos os oceanos.

Testudines são animais únicos por possuírem as cinturas escapular e pélvica interiorizadas num casco formado por placas ósseas suturadas, cobertas por um mosaico de escudos córneos epidérmicos. O casco, um caráter extremamente conservativo que mudou pouco em cerca de 200 milhões de anos, é composto por uma porção dorsal, a carapaça, e uma porção ventral, o plastrão. Ambas as porções são unidas por uma região comumente chamada de ponte.

A carapaça é constituída pela fusão das costelas, das vértebras e de diversos elementos de ossificação dérmica, enquanto o plastrão é formado anteriormente por clavículas e interclavículas e, posteriormente, por costelas abdominais (Pough et al., 1996).

A monofilia da ordem Testudines é inquestionável e está firmemente estabelecida. O quelônio mais antigo que se conhece é Odontochelys semitestacea, descrito por Li et al. (2008), a partir de amostras de 220 milhões de anos, escavadas em depósitos do Triássico Superior chinês. Porém, antes dessa descoberta, a história da ordem Testudines começava com o fóssil Proganochelys Baur, 1887, com cerca de 210 milhões de anos, o qual já tinha carapaça e plastrão completos. Para GAFFneY \& MeEker (1983) Proganochelys estaria relacionado aos Captorhinidae do Permiano devido às características da anatomia craniana, porém LEE (1996) considerou frágil essa ligação, uma vez que não existe, no registro fóssil, qualquer morfologia intermediária entre os dois grupos.
LeE (1997) relacionou os quelônios ao clado dos Pareiasauria, por ambos apresentarem características comuns: uma armadura dermal rígida sobre toda a região dorsal, costelas achatadas estendidas, lâmina escapular cilíndrica e algumas peculiaridades dos membros.

Gaffney \& Meylan (1988) consideraram os representantes de Proganochelyidea como os quelônios mais primitivos e o grupo-irmão de todos os quelônios conhecidos, motivo pelo qual ambos foram agrupados em Casichelydia. Casichelydia foi dividido em duas subordens monofiléticas: Pleurodira e Cryptodira (GAFFNEY et al., 1991).

Os indivíduos de Pleurodira retraem a cabeça para proteção sob a carapaça, flexionando o pescoço lateralmente, enquanto os de Cryptodira executam uma flexão sagital do pescoço.

A classificação, bem como as discussões detalhadas sobre a biogeografia das famílias recentes, seguem as propostas por PRITCHARD (1979), ERNST et al. (1989) e IVERSON (1992).

Subordem Cryptodira. Algumas tartarugas marinhas têm ampla distribuição, como a tartaruga de couro Dermochelys coriacea Vandelli, 1761, representante monotípico da família Dermochelyidae, que ocorre nos mares tropicais, subtropicais e temperados. Neste sentido, quatro das seis espécies da família marinha Cheloniidae têm distribuição circuntropical e subtropical por todo o globo.

Emydidae (10 gêneros e 35 espécies) e Bataguridae (23 gêneros e 59 espécies) já foram consideradas subfamílias reunidas em uma única família: Emydidae (sensu lato), a qual incluía a maioria das tartarugas de água doce do hemisfério norte. Os emidídeos alcançaram sua maior diversidade no leste da América do Norte e os batagurídeos no sudeste da Ásia. Entretanto, ambas famílias não ocorrem na África e Austrália. Já na América do Sul, tanto Emydidae como Bataguridae são representados, cada uma, por um único gênero: Trachemys Agassiz, 1857 e Rhinoclemmys Fitzinger, 1835, respectivamente.

Os quelônios terrestres, incluídos na família Testudinidae (12 gêneros e 50 espécies), são encontrados em todos os continentes, exceção à Austrália e à Antártica. Os jabutis alcançaram grande diversidade na África, ao sul do Saara. Os testudinídeos, apesar de terrestres, conseguem flutuar bem na água e são hábeis em atravessar barreiras oceânicas. Assim, colonizaram tanto margens continentais quanto remotas ilhas oceânicas.

As tartarugas de casco mole, Trionychidae, acolhem duas subfamílias: Cyclanorbinae (três gêneros e seis espécies) e Trionychinae (11 gêneros e 17 espécies). Atualmente, os trioniquídeos são registrados na África, na Ásia, no arquipélago Indo-Australiano e na América do Norte.

A família Carettochelyidae, monotípica, está restrita à Nova Guiné e ao norte da Austrália, enquanto Kinosternidae, representada por quelônios semiaquáticos, ocorre do Canadá à América do Sul e duas subfamílias são reconhecidas: Staurotypinae (dois gêneros e três espécies) e Kinosterninae (um gênero e 19 espécies). Dermatemydidae tem um único representante nos rios da América Central, Dermatemys mawii Gray, 1847. 
No que tange à Chelydridae, há dois gêneros nas Américas: Chelydra Schweigger, 1812 (três espécies), com distribuição do sul do Canadá ao Equador e Macroclemys temminckii Troost, 1835, restrito aos Estados Unidos. Conforme GafFney \& MeYlan (1988), Platysternon megacephalum Gray, 1831, asiática, também pertence a esta família, embora, por um longo tempo, se considerou Platysternidae como uma família monotípica.

Subordem Pleurodira. Constituída por três famílias, Podocnemidae, Pelomedusidae e Chelidae. Os podocnemídeos e os pelomedusídeos foram, por muito tempo, considerados apenas subfamílias (Podocneminae e Pelomedusinae) de uma grande família, Pelomedusidae, mas estudos recentes atribuíram a elas o status de família (SHAFFER et al., 1997).

Atualmente, a subordem Pleurodira está restrita aos continentes meridionais, sendo que Pelomedusidae (dois gêneros e 17 espécies) ocorre na África, incluindo Madagascar e outras ilhas do Oceano Índico. Os podocnemídeos (dois gêneros e sete espécies) estão distribuídos na América do Sul tropical, além de um gênero monotípico em Madagascar, embora a distribuição no passado tenha sido mais ampla; fósseis desta família foram encontrados na Europa, na Ásia e nos continentes africano e norte-americano.

Os quelídeos ocorrem na América do Sul e Austrália e é o único grupo de quelônios de origem gondwânica (GAFFney \& MEYlan, 1988). Estes autores reconheceram duas subfamílias: Pseudemidurinae, monotípica, com ocorrência na porção sudoeste da Austrália, e seu grupoirmão Chelinae (10 gêneros e 40 espécies), o qual inclui todos os outros táxons de quelídeos sul-americanos e australianos. SHAFFer et al. (1997) sugeriram que tanto as linhagens australianas quanto as sul-americanas podem ser grupos irmãos monofiléticos.

\section{Os quelônios continentais do Rio Grande do Sul}

\section{Família Chelidae Acanthochelys spixii (Duméril \& Bibron, 1835)}

Taxonomia. Segundo Fritz \& Havas (2007), a espécie foi descrita originalmente por Spix em 1824 como Emys depressa. Em 1835, foi renomeada para Platemys spixii por Dumeril \& Bibron e finalmente, em 1873, Gray a inclui no gênero Acanthochelys Gray, 1873 e a renomeou como Acanthochelys spixii. Emys aspera Cuvier, 1831, Hydraspis spixii Gray, 1844 e P. radiolata spixii Hoogmoed \& Gruber, 1983 foram sinonimizadas com $A$. spixii. No Rio Grande do Sul é conhecida popularmente como cágado-preto ou cágado-de-espinhos; em inglês, Spine-necked Swamp Turtle e Black Spine-Neck Swamp; e, em espanhol, tortuga de canaleta.

Descrição. Quelônio mediano (até $17 \mathrm{~cm}$ ) com tubérculos alongados e pontiagudos no pescoço. Carapaça elíptica e achatada, com sulco dorsal superficial entre a porção posterior do primeiro escudo vertebral até a região anterior do quinto escudo vertebral. Nos adultos, primeira e quinta vertebrais muito mais largas que longas, com a primeira mais larga que as demais; segunda a quarta vertebrais aproximadamente tão largas quanto longas e, às vezes, mais longas do que largas. Juvenis sem sulco vertebral mediano, podendo apresentar uma quilha medial baixa. Escudos marginais mais anteriores e mais posteriores mais largos, laterais mais estreitos. Marginais posteriores não serrilhadas a levemente serrilhadas. Escudos da carapaça, muitas vezes, com ranhuras radiadas e concêntricas. Carapaça mais alta quase antes da segunda sutura intervertebral e mais larga no nível do sétimo e oitavo escudo marginal. Carapaça nos adultos cinza-escura ou preta, ocasionalmente amarela na base das pleurais, provavelmente de origem pedomórfica, já que os neonatos têm manchas amarelas, alaranjadas ou vermelhas no plastrão. Lóbulo dianteiro do plastrão levemente voltado para cima, mais largo do que os lóbulos traseiros. Lóbulo traseiro com ampla fenda posterior. Cabeça verde olivácea a cinza; mandíbulas não fendidas amarelas a acobreadas. Face dorsal da cabeça recoberta por numerosas escamas variavelmente dispostas, as quais parecem arranjadas dentro de três ou quatro linhas laterais acima do tímpano. Focinho curto e levemente projetado. Duas pequenas barbelas cinzas no queixo. Íris branca. Dedos interligados com membranas; superfícies anteriores das patas cobertas por escamas largas. Várias linhas de tubérculos espinhosos sobre as coxas. Cauda relativamente curta e todas as partes macias do corpo verde oliváceo a cinza. Machos com plastrão côncavo, cauda mais longa e grossa, com abertura cloacal mais distal à margem da carapaça. Fêmeas com plastrão plano e cauda mais curta e cloaca mais proximal à margem da carapaça; escudo anal voltado para cima (CABRERA, 1998; ERNST et al., 1989).

Distribuição. Registrado no Uruguai (Rocha e Tucuarembó) e a oeste até as províncias de Formosa e Chaco (Argentina) (FriTz \& Havas, 2007). No Brasil, ocorre na Bahia, Minas Gerais, São Paulo ao Rio Grande do Sul (RHODIn et al., 1984; Ribas \& MonTEIRo FILHO, 2002) e no Distrito Federal (BRANDÃo et al., 2002).

Hábitat e ecologia. No Rio Grande do Sul, a espécie está associada a ambientes lagunares arenosos, banhados e charcos estacionais ou semipermanentes (Bujes, 2008; Bujes \& Verrastro, 2008). No Delta do Jacuí, foram encontrados indivíduos apenas em hábitats de águas lênticas, como banhados temporários, canais de irrigação, quadras de arroz, cavas (depressões originadas da ação humana pela extração de areia) e poças (BUJES \& VERRASTRO, 2008). Igualmente, foi registrada ocupando ambientes de águas lênticas e banhados temporários do Parque Estadual de Itapeva, em Torres (MiorAndo, 2006) e em pequenos corpos d'água temporários (LEMA, 2002), onde se verificaram migrações entre um e outro durante as noites de verão (LEMA \& FERREIRA, 1990).

Não existem estudos sobre a dieta de espécimes de vida livre no Rio Grande do Sul. Dados sobre reprodução são bastante escassos. Em março de 2006, na Ilha das Flores, foi capturada uma fêmea ovígera (metodologia de palpação) com $162 \mathrm{~mm}$ de comprimento linear da carapaça (CLC) (Clóvis S. Bujes, dados inéditos). Miorando (2006) registrou atividades reprodutivas em Itapeva, Torres, entre os meses de maio e dezembro e observou um comportamento de cópula em dezembro de 2005, uma fêmea nidificando em março e um neonato em abril de 2006, com CLC de 67,6 mm e peso de 55 g. Na mesma ocasião, acompanhou a construção de um ninho: uma 
cova simples efetuada sobre uma das elevações de duna, que permaneceu seca durante o ano todo, ao lado de vegetação herbácea/arbustiva; o ninho apresentou profundidade de $34,4 \mathrm{~mm}$ e maior largura de $89,6 \mathrm{~mm}$; os três ovos encontrados eram quase esféricos e a dimensão média dos diâmetros menor e maior foi de 24,43 x 26,16 $\mathrm{mm}$, respectivamente. O peso médio dos ovos foi $8,5 \mathrm{~g}$. A fêmea nidificante tinha CLC de 136,1 mm e pesava $405 \mathrm{~g}$, registrados após a oviposição.

Parâmetros populacionais. Em estudos realizados no Delta do Jacuí, foram capturados seis machos, nove fêmeas (razão sexual de 1,5 fêmea por macho) e um jovem (C. S. Bujes, dados inéditos). Os machos dessas subpopulações apresentaram CLC entre 134 e $176 \mathrm{~mm}$ e as fêmeas entre $149 \mathrm{e} 176 \mathrm{~mm}$. O único subadulto coletado tinha $116 \mathrm{~mm}$ de CLC. Dez destes exemplares foram capturados entre 19 e 22 horas, um às $18 \mathrm{~h}$ e outro às $8 \mathrm{~h}$. Os adultos apresentaram dimorfismo sexual acentuado: suave concavidade na região posterior do plastrão, caudas mais largas e mais compridas e abertura cloacal mais distal nos machos em relação às fêmeas com o mesmo CLC.

A amostra de uma população de Torres, estudada por Miorando (2006), era composta por 23 fêmeas, 21 machos e seis subadultos. As fêmeas apresentaram CLC médio de 136,43 mm (91,3 a 159,5 mm) e o CLC médio dos machos foi de $129,35 \mathrm{~mm}$ (82,9 a $154,7 \mathrm{~mm})$. O peso médio verificado para fêmeas e machos foi de 385,6 g (130 a 700 g) e 281,5 g (80 a $415 \mathrm{~g}$ ), respectivamente. Acanthochelys spixii apresentou atividade predominantemente crepuscular (30\% dos registros) e noturna (70\% dos registros). As atividades matutinas e vespertinas somadas atingiram 30\% dos registros. Miorando (2006) caracterizou a espécie como caminhadora de fundo, pouco se deslocando na coluna da água, o que pode estar relacionado ao comportamento de forrageamento e camuflagem.

\section{Hydromedusa tectifera Cope, 1870}

Taxonomia. A espécie foi descrita por CoPE (1870) como Hydromedusa tectifera, segunda espécie do gênero Hydromedusa Wagler, 1830. Foram estabelecidas duas sinonímias: $H$. platanensis Gray, 1873 e $H$. wagleri Günther, 1884 (FritZ \& HaVAS, 2007). Hydromedusa tectifera é conhecida popularmente como cágado-depescoço-de-cobra, cágado-de-pescoço-comprido, cágado-pescoçudo (português); South American SnakeNecked Turtle (inglês); tortuga cabeza de víbora (espanhol).

Descrição. Carapaça oval, relativamente achatada, lados aproximadamente paralelos, marrom-escura, de até 300 mm de CLC. Quilha medial em forma de protuberâncias cônicas posteriores sobre os escudos vertebrais 1-4; protuberância cônica no escudo vertebral 5 , bem desenvolvidas nos jovens, desaparecendo completamente nos indivíduos mais velhos. Protuberâncias similares nos escudos pleurais, que também desaparecem com a idade. Escudo cervical posterior ao primeiro par de marginais anteriores; osso nucal, localizado abaixo, alcança a borda da carapaça parcialmente entre o primeiro par anterior de ossos periféricos. Escudos vertebrais mais largos que longos nos jovens; nos adultos a primeira vertebral é tão longa quanto, ou ligeiramente mais longa, do que larga, achatada anteriormente. Vertebral 4 tão longa quanto larga; vertebral 5 expandida posteriormente. Somente seis neurais, os pares 7 e 8 dos ossos costais localizados na linha média. Vinte e dois ossos periféricos; marginais laterais ligeiramente voltadas para cima. Superfície ventral das marginais e ponte marrom ou amarelada com manchas marrons. Plastrão amarelo imaculado a amarelo com manchas marrons; lóbulo anterior mais largo do que o lóbulo posterior, mais ou menos arredondado anteriormente; lóbulo posterior com fenda posterior profunda. Cabeça de tamanho moderado, focinho curto e ligeiramente projetado. Superfície dorsal coberta por numerosas escamas dispostas irregularmente. Coloração da cabeça verde-oliva a cinza, com ampla listra creme ou branca margeada de preto que se estende da mandíbula superior para trás, ao longo do pescoço. Mandíbula superior sem entalhes ou bicos. Queixo e face ventral do pescoço amarelos com vermiculações ou ocelos pretos; mandíbulas amarelas ou bronzeadas. Pescoço mais longo que o restante da coluna vertebral; superfície lateral revestida de numerosos tubérculos em forma de espinhos. Membros verde-oliva a cinza sobre a superfície dorsal e creme a amarelo, ventralmente. Patas dianteiras com escamas transversais largas sobre a superfície anterior; escamas similares nos calcanhares e acima da superfície posterior das patas traseiras. Quatro garras em cada pata. Cauda cinza-olivácea. Machos com plastrão côncavo, fenda anal profunda; caudas mais grossas, maiores e abertura cloacal mais distal, em relação a das fêmeas. Fêmeas atingem tamanhos maiores (ERNST et al., 1989; CABRERA, 1998).

Distribuição. Paraguai, Uruguai, Argentina e extremo sudeste da Bolívia (Lema \& FerReIRA, 1990). No Brasil, Rio Grande do Sul (FAGUNDES \& BAGER, 2007), Santa Catarina (Ghizoni-JR \& GraiPel, 2005), Paraná (Ribas \& Monteiro Filho, 2002), São Paulo (Ferronato et al., 2009), Rio de Janeiro (Rocha et al., 2004) e Minas Gerais (SousA \& Novelli, 2009).

Hábitat e ecologia. No Rio Grande do Sul, a espécie é comum em banhados com baixo fluxo de água (LEMA \& FERREIRA, 1990), banhados temporários de águas lênticas, com vegetação abundante (BUJES \& VerRastro, 2008), tanto em ambientes preservados (FAGUNDES \& BAGER, 2007), quanto em hábitats com intensa presença humana (e.g. Parque Moinhos de Vento e canal da Ilha Mauá, Porto Alegre). Lema \& Ferreira (1990) encontraram indivíduos enterrados em locais secos e na lama durante o inverno, e que retornaram à superfície somente na primavera.

As fêmeas realizam oviposições isoladas. No banhado do Taim, FAGUNDES \& BAGER (2007) observaram atividades de nidificação e desova nos meses de novembro e dezembro, sendo que $77,3 \%$ destas ocorreram na segunda quinzena de novembro, a poucos metros da margem (média $=8,2 \mathrm{~m}$ ) e em áreas com certo grau de declividade (média $=26,2^{\circ}$ ). No Parque Moinhos de Vento as ninhadas também ocorreram entre novembro e dezembro, porém a menos de dois metros da margem, o que pode ser reflexo do ambiente local (C. S. Bujes, obs. pess.). O número de ovos por ninhada variou de quatro a seis ovos (Lema \& FerReIRA, 1990) ou de sete a 15 ovos, 
nestas últimas, com quantidade média de 11,6 ovos por ninho (FAGUndes \& BAGER, 2007). No Parque Moinhos de Vento a maior quantidade de ovos encontrada foi de oito por ninho (C. S. Bujes, obs. pess.). Os ovos eram elípticos, apresentando casca calcária e de coloração branca, com a média dos diâmetros maior e menor 36,5 e 23,9 mm, respectivamente (FAGUNDES \& BAGER, 2007). Os diâmetros médios, maior e menor, dos ovos encontrados no Parque Moinhos de Vento foram de 37,11 (extremos em 33,7 a 40,4 mm) e 23,63 mm (extremos de 23,3 a $24 \mathrm{~mm}$ ) e o peso entre 10,8 e 13,5 g, média de 12,24 g (C. S. Bujes, obs. pess.).

Parâmetros populacionais. São poucas as informações sobre a dinâmica populacional no Brasil. Bujes \& Verrastro (2008) observaram no delta do Jacuí, Rio Grande do Sul, que as populações possuem baixa densidade. Nesta região, foram capturados 11 animais: seis fêmeas e cinco machos (todos entre 22 e 6 h). O comprimento linear da carapaça das fêmeas variou de 168 a 263 mm e o peso entre 1110 a $1200 \mathrm{~g}$; nos machos o CLC oscilou entre 170 a $224 \mathrm{~mm}$, e o peso 1045 a $1180 \mathrm{~g}$ (C. S. Bujes, obs. pess.).

\section{Phrynops geoffroanus (Schweigger, 1812)}

Taxonomia. As três espécies de Phrynops Wagler, 1830 citadas para o Rio Grande do Sul, $P$. geoffroanus, $P$. hilarii Duméril \& Bibron, 1835 e $P$. williamsi Rhodin \& Mittermeier, 1983, bem como P. tuberosus (Peters, 1870) (com distribuição da Venezuela até o estado da Bahia, pela porção norte oriental da América do Sul) compõem um complexo denominado P. geoffroanus (Rhodin \& Mittermeier, 1983). Quanto à taxonomia deste grupo, persiste a divergência entre os pesquisadores: alguns sustentam que este taxón seja uma super-espécie, suscetível a ser fracionada em várias unidades específicas, outros argumentam que esta é uma espécie politípica com várias subespécies diferentes (RUEDA-ALMONACID et al., 2007). Estes autores apóiam a ideia de que a extensa distribuição geográfica do grupo e a escassez de material científico não permitem estabelecerem os complexos padrões de coloração de cada uma das populações e quantificar as diferenças morfométricas do casco. Além disso, muitas populações tidas como $P$. geoffroanus parecem corresponder a uma forma ainda não identificada. É popularmente conhecida por cágado-de-barbicha, cangapara, lalá, cágado-do-rio, tartaruga-do-pescoço-decobra (português); Geoffroy's Side-Necked Turtle (inglês); bachala, huele feo (espanhol).

Descrição. Carapaça oval e aplanada. Cabeça pequena, estreita em relação ao corpo, coberta com escamas pequenas e irregulares. Mandíbula superior sem bico ou entalhe. Pescoço com tubérculos discretos. Coloração vermelha com manchas pretas na garganta e na ponte, em imaturos; coloração esmaecida, em adultos. Plastrão amarelo-ocre ou castanho-amarelado. Carapaça escura, do marrom claro ao preto. Escudos geralmente rugosos e/ou com estrias salientes. Plastrão bem desenvolvido com entalhe anal; lóbulo anterior ligeiramente mais largo que o posterior. Ponte relativamente larga. Intergular completamente separado das gulares. Porção ventral dos escudos marginais, ponte e plastrão amarelo uniforme a marrom claro, nos adultos mais velhos; nos juvenis e adultos jovens, vermelho e plastrão enegrecido. Cinco garras nos membros anteriores e quatro nos posteriores. Dimorfismo sexual em tamanho e massa: machos são menores e menos pesados, possuem caudas mais compridas, grossas e aberturas cloacais mais distais em comparação com as fêmeas. Indivíduos jovens podem apresentar uma quilha mediana na carapaça, que desaparece nos adultos. Fêmeas adultas podem alcançar até $350 \mathrm{~mm}$ de comprimento e ter massa de 2,5 $\mathrm{kg}$ (ERNST et al., 1989; RuEDA-AlmONACID et al., 2007).

Distribuição. De todos os membros de Chelidae, $P$. geoffroanus apresenta a distribuição geográfica mais ampla. Ocorre na Amazônia, Colômbia, Equador, Peru e Bolívia até o norte da Argentina e Paraguai e, possivelmente no Uruguai (RuedA-AlmonACID et al., 2007). No Brasil, a espécie é registrada na Bacia Amazônica, nos estados do Pará, Amazonas (Vogt, 2008) e Rondônia (FACHín-Terán et al., 1994; Vogt, 2008; SCHNEIDER et al., 2009); na Região Sudeste, em Minas Gerais (Vogt, 2008), São Paulo (SouZA \& ABe, 2001; Vogt, 2008; Ferronato et al., 2009; Pinã et al., 2009) e Rio de Janeiro; na Região Centro-Oeste, no Mato Grosso do Sul (Souza et al., 2008) e Goiás; na Região Nordeste, no Maranhão, Piauí, Ceará, Rio Grande do Norte (Torres et al., 2009); e, na Região Sul, Paraná (RIBAS \& MonteIro FILHO, 2002) e noroeste do Rio Grande do Sul (LEMA, 1994).

Hábitat e ecologia. Pritchard \& Trebbau (1984) reportaram três a 30 ovos, ou a média de 15,2 ovos por ninhada. Os ovos apresentaram comprimento médio de 31,1 mm e largura média de 31,5 mm. Em estudos realizados em rios urbanos por SouzA (1999) e SouzA \& ABE (2001), P. geoffroanus se mostrou menos ativa nas estações chuvosas e exibiu maior atividade entre os meses de setembro a novembro, período associado às altas temperaturas do ar. A nidificação ocorreu entre fevereiro e agosto e cada ninhada composta de oito a 20 ovos, com tamanho médio de 29,3 mm de comprimento e 28,4 de largura. A menor fêmea nidificante tinha $262 \mathrm{~mm}$ de CLC. A espécie apresentou um evento reprodutivo por ano. No Paraná, indivíduos foram amostrados entre altitudes de 260 e 975 m, utilizando lagos, rios, cavas de areia e valetas de esgoto, parecendo muito bem adaptados aos ambientes contaminados com dejetos orgânicos nas periferias das cidades (RIBAS \& MonTEIRO FILHO, 2002). RUEDA-ALMONACID et al. (2007) relataram que indivíduos ocorrem em rios de correntezas ou sinuosos, canais e lagos com abundante vegetação aquática e com matas de galeria e dossel fechado nas suas margens. A reprodução ocorreu durante a estação seca, entre dezembro e abril, quando o nível dos rios desce, dando origem a praias arenosas; espécimes desovaram ao anoitecer, depositando entre 10 a 20 ovos com diâmetro de cerca de $30 \mathrm{~mm}$; a eclosão dos ovos se deu entre 115 e 186 dias. O CLC das fêmeas não superou $350 \mathrm{~mm}$. Segundo VoGt (2008), indivíduos são abundantes principalmente próximo às nascentes de córregos e sob cachoeiras, onde a água é bem aerada. A reprodução iniciou-se em junho e se estendeu até agosto. As fêmeas registradas neste estudo atingiram até $390 \mathrm{~mm}$ de CLC e migraram por centenas de metros até atingirem um local com áreas abertas e vegetação rasteira para, então, nidificarem. 
Neste local, as fêmeas desovaram isoladamente, produzindo até quatro ninhadas de, aproximadamente, 28 ovos com $32 \mathrm{~mm}$ de diâmetro médio em ninhos de 80 a $100 \mathrm{~mm}$ de profundidade.

Parâmetros populacionais. SouZA \& ABE (2000), em Ribeirão Preto (SP), registraram elevada densidade de indivíduos em rios urbanos, cerca de 170 a 230 por hectare de rio. A biomassa estimada neste estudo foi de 255 a 345 $\mathrm{kg} / \mathrm{ha}$ de rio. Não existem informações demográficas sobre a espécie no Rio Grande do Sul.

\section{Phrynops hilarii Duméril \& Bibron, 1835}

Taxonomia. Segundo FrITz \& Havas (2007), a espécie foi descrita como Platemys hilarii, em 1835, tendo como sinonímias Hydraspis hilarii Gray, 1856, Spatulemys lasalae Gray, 1872, H. geoffroyanus hilarii Siebenrock, 1905 e $P$. geoffroanus hilarii Wermuth \& Mertens, 1961. Não há subespécies descritas para esse táxon e permanecem as divergências comuns ao gênero, mencionadas anteriormente em $P$. geoffroanus. É popularmente conhecida como cágado-de-barbelas, cágado-cinza, cágado-de-lagoa (português); Hilaire's Side-Necked Turtle (inglês); tortuga de laguna, campanita (espanhol).

Descrição. Atingem até $400 \mathrm{~mm}$ de comprimento. Carapaça oval, achatada, com lados paralelos e mais largos próximo ao centro. Suave quilha na linha medial nos indivíduos mais jovens. Escudos vertebrais 1-3 e 5 mais largos do que longos nos adultos; 4 tão longo quanto ou mais longo do que largo (todos são mais largos do que longos nos jovens); o primeiro mais largo, expandido anteriormente e o quinto expandido posteriormente. Escudo cervical, na maioria das vezes, longo e reduzido. Carapaça com escudos geralmente rugosos; coloração marrom-escura, verde-oliva ou cinza com uma borda amarelada. Plastrão desenvolvido, com entalhe anal. Lóbulos frontais muito mais largos que os posteriores; ponte relativamente larga. Superfície ventral dos escudos marginais, ponte e plastrão amarelados com numerosas manchas pretas dispostas irregularmente. Cabeça grande e larga; focinho projetado; presença de duas barbelas bicolores no mento; mandíbula superior carece tanto de entalhe quando de um bico. Cabeça coberta com escamas dispostas irregularmente, com um escudo frontal proeminente; coloração cinza e/ou verde-oliva dorsalmente; uma listra preta, pronunciada, sobre cada um dos lados, se inicia no rostro e segue para trás, cruzando por dentro da órbita e por cima do tímpano, até o pescoço. Abaixo desta listra, cabeça e pescoço brancos ou cremes. Outras duas linhas pretas em cada um dos lados da garganta, iniciando atrás da barbela e indo para trás, às vezes, unindo-se à listra preta superior. Mandíbulas amarelas; pescoço pode conter alguns tubérculos agudos grossos. Membros seguem o padrão de coloração da cabeça: superfície dorsal e laterais cinzaoliva e superfície ventral creme; sola e palmas das patas podem ser pretas. Machos com cauda mais longa e grossa e uma suave concavidade no plastrão (ERNST et al., 1989; CABRERA, 1998).

Distribuição. Região centro-oriental da América do Sul: Paraguai, Uruguai e nordeste da Argentina (LEMA \&
Ferreira, 1990; Fritz \& Havas, 2007). No Brasil, é amplamente distribuída no estado do Rio Grande do Sul (LEMA, 1994; BAGER, 1997; BuJEs, 2008; BuJES \& VERRASTRO, 2008, 2009). TORTATo (2007) registrou a espécie no Parque Estadual da Serra do Tabuleiro, em Santa Catarina.

Habitat e Ecologia. Costuma ocupar ambientes lênticos e lóticos (BuJEs \& VERRASTRo, 2008). Indivíduos nidificam, com maior frequência, em solos arenosos, cobertos com vegetação herbácea (BAGER, 1997; BUJES, 1998), depositando mais de uma ninhada por evento reprodutivo (Bujes, 1998; Bujes \& VerRastro, 2009); a estação reprodutiva ocorre em dois eventos anuais: de fevereiro a maio e de setembro a dezembro, na Estação Ecológica do Taim (BAGER, 1997) e de março-abril e setembro-outubro, na Reserva Biológica do Lami e no delta do Rio Jacuí (Bujes, 1998; Bujes \& Verrasto, 2009) ambos no Rio Grande do Sul. Estes eventos parecem estar intimamente associados à temperatura da área de distribuição: no inverno de 2004, após uma semana de temperaturas elevadas, houve registro de uma fêmea que nidificou na Fazenda Kramm, Delta do Jacuí (C. S. Bujes, obs. pess.). O número de ovos por ninhada variou de 1 a 23, com maior e menor diâmetro, em média, 32,6 e 31,9 mm, respectivamente (BAGER, 1997). BuJEs (1998) registrou a média de 11 ovos por ninho na Reserva do Lami e os ninhos apresentaram de 100 a $150 \mathrm{~mm}$ de profundidade. No Delta do Jacuí, as medidas dos ovos equivaleram em média 34 x $32 \mathrm{~mm}$ e o peso médio foi de $21,5 \mathrm{~g}$. O período de incubação variou de 157 a 271 dias, em ambiente natural e de 130 a 191 dias sobre condições artificiais (BUJEs \& Verrastro, 2009). A distância dos ninhos ao corpo d'água mais próximo oscilou entre 3 (Souza et al., 2006) e $80 \mathrm{~m}$ (BuJEs, 1998). BAGER (1997) registrou ninhos em distâncias entre 30 e $200 \mathrm{~m}$ do recurso hídrico.

Parâmetros populacionais. No Rio Grande do Sul, é a segunda espécie mais abundante (BuJEs \& VERRASTRO, 2009), formando agrupamentos de muitos indivíduos em populações e subpopulações no Delta do Jacuí, arroio do Lami (Bujes, 1998) e ao longo do Lago Guaíba (C. S. Bujes, obs. pess.). No estudo de BAGER (1997), na Estação Ecológica do Taim, foram coletadas 45 fêmeas e 20 machos. Peres (2010), em uma população de área urbana, registrou 53 exemplares (16 machos, 25 fêmeas e 12 de sexo não determinado - SND) e a abundância estimada em 282,67 indivíduos, correspondendo à biomassa de $59 \mathrm{~kg} / \mathrm{hectare}$; a razão sexual observada foi de 1,56 fêmeas para 1 macho. Em algumas populações estudadas, as fêmeas atingiram tamanhos de CLC máximo de 531 mm (BAGER, 1997) e 350 mm (Bujes, 1998). A taxa de predação de ninhos, numa população acompanhada por Bujes (1998), ficou em $82,35 \%$ dos ninhos observados.

\section{Phrynops williamsi Rhodin \& Mittermeier, 1983}

Taxonomia. A espécie foi descrita tendo como localidade-tipo o rio Cadeia, afluente da margem esquerda do rio Caí, no Rio Grande do Sul, e não possui sinonímias (FRITZ \& HAVAS, 2007). Tem como nomes comuns cágadorajado, cágado-de-ferradura (português); William's SideNecked Turtle, William's Toadhead Turtle (inglês); e Tortuga de la Herradura (espanhol).

Descrição. Espécie relacionada a $P$. geoffroanus e 
P. hilarii. Carapaça oval de até $350 \mathrm{~mm}$ de CLC, com cúpula moderada e mais larga no centro; bordas das marginais levemente serrilhadas; pequeno entalhe supracaudal; vertebral 1 a maior e todas as vertebrais mais largas do que longas; ausência de quilhas nas vertebrais dos adultos. Escudo cervical cerca de duas vezes mais longo do que largo. Coloração da carapaça castanha com faixas estreitas rajadas sobre todos os escudos, limitados por uma fina faixa laranja ou amarela. Plastrão bem desenvolvido, cinza a amarelo, sem manchas; entalhe anal presente; escudos gulares completamente separados pelo intergular. Cabeça moderadamente estreita, com focinho projetado; mandíbula superior sem bico ou fenda; duas barbelas no queixo. Pele sobre o focinho, região interorbital e terceira metade da superfície dorsal da cabeça incompletamente separada por escamas; restante da superfície da cabeça coberta por escamas pequenas dispostas irregularmente. Cabeça escura dorsalmente, com várias estrias avermelhadas nos juvenis; superfície ventral do queixo e do pescoço geralmente branca, às vezes vermelhoamarelada ou amarelada. Três faixas pretas largas subparalelas em cada lado da cabeça: (1) uma dorsal que se estende das narinas, passando pela órbita e parte superior do tímpano, até o pescoço; (2) uma mediana posteriormente ao ângulo da mandíbula até o tímpano e sobre a superfície ventrolateral do pescoço; (3) uma estreita faixa ventral, posteriormente direcionada, semelhante a uma ferradura, sobre a superfície inferior do queixo, de onde se projeta um par de barbelas. Crânio com grande cobertura parietal, arco temporal curto e grosso, nenhum contato exoccipital ao forâmen magno, processo troclear divergindo amplamente, superfícies maxilares trituradoras anteriormente amplas com sulcos curtos e mandíbula em forma de pá. Pescoço pode conter alguns tubérculos duros e bem definidos. Superfície dos membros negra a marrom com padrão vermicular distinto; porções inferiores amarelo-avermelhadas ou amarelas; dedos podem ser avermelhados (ERNST et al., 1989; CABRERA, 1998).

Distribuição. Registrada para Uruguai, Paraguai e nordeste da Argentina (CABRERA, 1998). No Brasil, no Paraná (Ribas \& Monteiro FilHo, 2002), em Santa Catarina (Cielusinsky et al., 2008) e, no Rio Grande do Sul, nas localidades de Butiá, Dom Pedrito, Jaguarão, Santana do Livramento e São Leopoldo (C. S. Bujes, obs. pess.).

Hábitat e ecologia. São animais diurnos que ocupam hábitats de córregos e rios de florestas com leito rochoso, não ocorrendo em simpatria com outros quelônios: BuskiRK (1989) encontrou P. williamsi no Rio Jaguarão, limite Brasil-Uruguai, somente em locais onde não ocorriam outras espécies, como T. dorbigni e $H$. tectifera. As fêmeas ao atingirem $250 \mathrm{~mm}$ já estão aptas à reprodução (RHODIN \& MITTERMEIER, 1983). Desovam, em média, sete ovos (de cinco a nove) por ninho, cujo tamanho médio é de 33,3 por 27,0 mm (RHodin \& MitTermeier, 1983; Cabrera, 1998). Os ninhos foram construídos próximos a bancos de areia, entre os meses de outubro a janeiro (RHOdin \& MitTERMEIER, 1983). Em junho, foi encontrado um filhote de $35 \mathrm{~mm}$ deambulando, ainda com dente-do-ovo, com saco vitelínico vestigial e a carapaça lateralmente comprimida (BUSKIRK, 1989), o que pode sugerir que a eclosão ocorra neste período do ano. Pouco se conhece sobre o hábito alimentar de $P$. williamsi, porém as modificações em suas mandíbulas remetem a animais que se alimentam triturando conchas de moluscos, artrópodes aquáticos e peixes (BUSKIRK, 1989).

Parâmetros populacionais. Não existem estudos demográficos sobre essa espécie no Rio Grande do Sul. Observações esporádicas indicam que as populações têm baixa densidade se comparadas àquelas de populações de espécies similares (e.g. P. hilarii) (C. S. Bujes, obs. pess.).

\section{Família Emydidae \\ Trachemys dorbigni (Duméril \& Bibron, 1835)}

Taxonomia. Originalmente descrito como Emys dorbigni (FrITz \& HaVAs, 2007), é um dos quelônios mais abundantes no Rio Grande do Sul; é conhecido popularmente como tartaruga-tigre, tartaruga-tigred'água (português); Brazilian slider, D'Orbigny slider turtle (inglês); morrocoyo, tortuga pintada (espanhol) (Bujes \& Verrastro, 2007). Freiberg (1969) descreveu duas subespécies, $T$. $d$. dorbigni com ocorrência no Uruguai e Argentina e $T$. $d$. brasiliensis no Brasil. BARCO \& LARRIERA (1991) constataram que as características morfológicas analisadas por FREIBERG (1969) se tratavam de variações ontogenéticas e eram geograficamente inconsistentes.

Descrição. Animais de até $267 \mathrm{~mm}$ de CLC. Carapaça oval a alongada, moderadamente convexa (mais ainda nas fêmeas), quilha medial baixa (mais pronunciada nos juvenis), posteriormente serrilhada. Escudos vertebrais, geralmente, mais largos do que longos. Coloração marrom a verde-oliva, com manchas de formas variadas e tons avermelhados, alaranjados e/ou amarelos sobre cada escudo. Cada escudo marginal com uma barra vertical claramente colorida. Juvenis com inúmeras áreas claras vazias as quais tornam-se progressivamente mais escuras com a idade até que toda a superfície do plastrão se torne escura. Machos apresentam melanização ontogenética: a pele dos membros, cabeça e cauda torna-se enegrecida; os tons coloridos da carapaça e plastrão sofrem despigmentação e/ou esmaecem. Cabeça de tamanho moderado; focinho pontudo, pouco projetado, leve entalhe na mandíbula superior. Cabeça verde a marrom, com numerosas listras amarelas ou laranjas delimitadas de preto. Listra supratemporal não atinge, ou toca levemente, a órbita. Abaixo disso, nas laterais, três listras mais estreitas que dirigem-se da órbita ao pescoço e, então, outra listra grande segue da superfície superior da órbita para baixo e para trás do pescoço. Focinho com várias listras estreitas de cada lado. Queixo com várias listras longitudinais, no meio do qual se ampliam e se bifurcam à medida que passam para trás em direção ao pescoço. Em cada canto da boca, uma mancha alongada bordeada de preto. Membros e pescoço verdes a marrons, com listras amarelas (ERNST et al., 1989; CABRERA, 1998).

Distribuição. Uruguai e nordeste da Argentina (VANZOLInI, 1997). No Brasil, ocorre no Rio Grande do Sul (ERnst, 1990; BAGER et al., 2007b; Fagundes, 2007; GonçALVES et al., 2007; BujEs, 2008) e sul de Santa Catarina (Bujes \& VerRastro, 2007; 2008). 
Hábitat e ecologia. Ocupa ambientes aquáticos como lagunas, rios, banhados, lagos e açudes com abundância de vegetação (BujEs, 2008), como a lagoa Mangueira e Estação Ecológica do Taim; banhados formados pelas águas do rio Santa Bárbara, em Pelotas; banhados, arroios e meandros formadores do Delta do rio Jacuí e Reserva Biológica do Lami, em Porto Alegre (C. S. Bujes, obs. pess.). No Delta do Jacuí, indivíduos foram observados ocupando diferentes tipos de hábitats, desde ambientes permanente ou temporariamente encharcados, até fortemente antropizados como canais de esgoto e de drenagem de água das plantações de arroz com deposição de agrotóxicos (Bujes \& VerRASTRo, 2007).

Quanto à dieta, foi considerado onívoro oportunista por HAHN (2005), que encontrou dieta diferencial entre machos e fêmeas e cerca de 37 itens alimentares de origem animal e vegetal. O comportamento alimentar na natureza foi descrito por BujEs et al. (2007), que também verificaram a predação sobre o mexilhão-dourado Limnoperna fortunei (Dunker, 1857), bem como o consumo de gastrópodes nativos da região (Hydrobiidae), Trichodactylus sp. (Crustacea), material vegetal (Poaceae, Angiospermae), areia e material sintético (e.g. linhas de pesca).

O período reprodutivo, na Estação Ecológica do Taim, foi registrado entre o final de setembro de 1980 e meados de fevereiro de 1981 (KRAUSE et al., 1982) e entre outubro e janeiro, nos anos de 1995 a 2001 (BAGER et al., 2007b). Na região do delta do rio Jacuí, de 4 de setembro de 2004 a 12 de fevereiro de 2005 (C. S. Bujes, obs. pess.). As fêmeas efetuam mais de uma ovipostura por estação reprodutiva: VANZOLINI (1997) registrou dois eventos, enquanto FAGUNDES (2007) reportou que $11,9 \%$ das fêmeas nidificantes realizaram duas oviposturas no período de 22 de outubro de 2006 a 4 de janeiro de 2007 , em Pelotas. BAGER et al. (2007b) verificaram que $16 \%$ das fêmeas nidificantes produziram duas e $14 \%$ produziram três oviposturas; os mesmos autores observaram 82 fêmeas em processo de ovipostura e 139 ninhos entre 1995 e 2001 no extremo sul do Brasil. GonÇalves et al. (2007) registraram a densidade de até nove ninhos por hectare, em área em Pelotas. Na Ilha da Pintada, no delta do Jacuí, em um único sítio de nidificação, com pouco mais de $90 \mathrm{~m}^{2}$, foi encontrado 32 ninhos (C. S. Bujes, obs. pess.). Estes ninhos apresentaram tamanho da abertura entre 42 e 49 mm, tamanho da câmara de incubação entre 85 e $100 \mathrm{~mm}$ e profundidade média do ninho $116,92 \mathrm{~mm}$. Indivíduos constroem ninhos de maneira solitária (GonÇALVES et al., 2007; FAgundes, 2007; BuJEs, 2008), porém, dependendo da disponibilidade de locais para a nidificação, pode ocorrer destruição dos mesmos em virtude da atividade de outras fêmeas sobre ninhos já finalizados, o que foi observado, por duas ocasiões, em um sítio de desova reduzido na Ilha da Pintada, Porto Alegre (C. S. Bujes, obs. pess.).

FAGUNDES (2007) e BAGER et al. (2007b) relataram oviposição anual em 35,3\% da população de fêmeas do arroio Santa Bárbara, Pelotas, e em $31 \%$ da população da Estação Ecológica do Taim, respectivamente. Os ninhos foram construídos a uma distância que variou de 0,4 a 160,5 m em relação ao curso d'água mais próximo, depositados isoladamente, porém com disposição agregada (GonçALVES et al., 2007; FAGUndes, 2007).
Os ovos de T. dorbigni são elípticos, flexíveis, com casca coriácea e branco-amarelados (KRAUSE et al., 1982). O número de ovos por ninho variou de 6 a 19 (KRAUSE $e t$ al., 1982; BAGER et al., 2007b), de 4 a 15 (FAGUNDES, 2007) e de 5 a 15 (C. S. Bujes, obs. pess.). A média de ovos por ninhada foi de 11,6 (KRAUSE et al., 1982), 12,1 (BAGER et al., 2007b), 8,2 (FAgundes, 2007) e 8 (C. S. Bujes, obs. pess.). O tamanho dos ovos oscilou entre $35,5-44$ por 22 $27 \mathrm{~mm}$ (KRAuse et al., 1982), 35,1-45,9 por 24-28,4 mm (BAGER et al., 2007b) e 31,7-45,4 por 19,6-28,4 mm (C. S. Bujes, obs. pess.).

As menores fêmeas registradas em atividades de oviposição apresentaram 198 mm (BAGER et al., 2007b), 176 mm (FAgundes, 2007) e 172 mm (C. S. Bujes, obs. pess.) de comprimento retilíneo da carapaça. Os menores machos, identificados com características sexuais secundárias bem definidas, mediram 132 mm (BAGER, 2003) e $127 \mathrm{~mm}$ (FAGUNDES, 2007) no comprimento retilíneo. No Delta do Jacuí, as fêmeas alcançaram CLC médios de 203,08 mm, e os machos, 179,93 mm, (BuJes, 2008); no extremo sul do Rio Grande do Sul, BAGER et al. (2007b) registraram fêmeas com $278 \mathrm{~mm}$ e machos com $225 \mathrm{~mm}$.

Os neonatos eclodiram, em média, com $36,42 \mathrm{~mm}$ (32,4 a 39,8 mm) de comprimento linear da carapaça (C. S. Bujes, obs. pess.). BAGER et al. (2007a) registraram neonatos com CLC médio de $35,1 \mathrm{~mm}$ e verificaram que neonatos que hibernavam no ninho, ao emergirem, tinham média relativamente menor e igual a $32,0 \mathrm{~mm}$.

Parâmetros populacionais. BAGER (2003) caracterizou uma população no extremo sul do Rio Grande do Sul com 210 indivíduos adultos (104 fêmeas e 106 machos), sendo as fêmeas maiores que os machos em comprimento da carapaça. FAGUndes (2007), em um ano de amostragem no arroio Santa Bárbara, em Pelotas, coletou 377 indivíduos (160 fêmeas, 146 machos e 71 juvenis). As subpopulações estudadas no Delta do Jacuí, mostraram-se ativas entre os meses de agosto e abril e foram representadas por poucos indivíduos agregados em localidades específicas dentro daquela área (BUJEs, 2008); foram coletados 137 indivíduos: 30 machos, 93 fêmeas e 14 jovens, em três pontos amostrais. A densidade foi calculada em 19, 7,3 e 4 indivíduos/ha e a respectiva biomassa foi de $20,73 \mathrm{~kg} / \mathrm{ha}, 8,32 \mathrm{~kg} / \mathrm{ha}$ e $4,96 \mathrm{~kg} / \mathrm{ha}$. A análise das curvas de crescimento individual, em exemplares de um açude no município de Guaíba (Rio Grande do Sul), demonstrou que, em um período de cinco anos, os machos cresceram $150 \mathrm{~mm}$ e as fêmeas, $185 \mathrm{~mm}$ (Pereira \& Diefenbach, 2001).

\section{Estado de conservação}

Nove espécies de quelônios dulciaquícolas foram reconhecidamente extintas pelo homem moderno. Somente um terço dos quelônios terrestres e aquáticos ainda pode ser considerado fora de perigo, dado que muitas espécies estão em risco de extermínio (GibBons et al., 2000; Mitchell \& Klemens, 2000). As populações têm declinado em taxas alarmantes por todo o mundo, com íntima relação com as atividades humanas, principalmente pela destruição e fragmentação de hábitats (GibBons et al., 2000), seguida da caça de subsistência, do tráfico para abastecer mercados de animais de 
estimação e de produtos usados na medicina tradicional - sobretudo asiática -, da competição com espécies invasoras, da poluição e do aquecimento global.

No ano de 2003 foi divulgada pelo Fundo de Conservação das Tartarugas, a lista vermelha das 25 espécies mais ameaçadas (JoHn, 2003). Nesta lista constavam duas espécies da América do Sul, uma da América Central, doze da Ásia, três de Madagascar, duas da África do Sul, duas dos EUA, duas da Austrália e uma do Mediterrâneo. Dentre estas 25 espécies, 18 são aquáticas e 21 vivem em regiões de alta diversidade biológica - os chamados hotspots -, onde a vegetação original já foi alterada em mais de $70 \%$.

Conforme o GeoBrasil (John, 2003), do Ministério do Meio Ambiente brasileiro, pelo menos seis espécies de quelônios estariam ameaçadas de extinção. No entanto, o Instituto Brasileiro de Meio Ambiente e Recursos Naturais Renováveis, do mesmo ministério, incluiu somente o cágado Mesoclemmys hogei (Mertens, 1967) em sua lista oficial de espécies da fauna brasileira ameaçada.

O estado de conservação dos quelônios do Rio Grande do Sul é desconhecido e as poucas e fragmentadas informações disponíveis são obtidas de relatos ocasionais de pesquisadores que, muitas vezes, não tinham estes répteis como objetos de estudo. As espécies que são consideradas abundantes e que não constam nas listas de espécies ameaçadas como $H$. tectifera, $P$. hilarii e $T$. dorbigni podem estar com seus status mal amostrados e, portanto, em perigo potencial devido, principalmente, à destruição avançada de seus hábitats (Bujes, 2008; Bujes \& Verrastro, 2009). Acanthochelys spixii está relacionada na Lista Vermelha de Espécies Ameaçadas da IUCN desde 1996, na categoria baixo risco ou próximo de ameaçada, por insuficiência de conhecimento (IUCN, 2010). Sobre a história de vida de P. geoffroanus e P. williamsi no Rio Grande do Sul, o desconhecimento é quase completo. As poucas informações apresentadas neste trabalho foram obtidas de estudos realizados há mais de vinte anos (e.g. RHodiN \& MitTERMEIER, 1983; BUSKIRK, 1989); essas contribuições apontam para espécies restritas a ambientes lóticos de rios e arroios, com fundo rochoso, ambientes esses que, na maioria das vezes, são os preferenciais à construção de barragens e hidrelétricas, o que ameaça o hábitat original das espécies. Apesar de não figurar na lista da IUCN (IUCN, 2010), P. williamsi está categorizada como "espécie em perigo" no Uruguai e como "insuficientemente conhecida" na Argentina (BERTONATTI, 1994). No Brasil, os dados sobre a espécie são insuficientes para incluí-la na lista de animais ameaçados.

Ameaças à sobrevivência. BuJES \& VERRASTRo (2008) listaram uma série de ameaças às populações de quelônios da região do delta do rio Jacuí, entre elas: perda e degradação de hábitats devido a práticas humanas como atividades agropecuárias e industriais, assentamento, fogo, uso indevido da água para irrigação, poluição da água e das terras adjacentes por despejo de agrotóxicos, esgoto residencial, comercial e industrial. Essas ameaças afetam, direta ou indiretamente, todas as espécies de quelônios abordadas neste trabalho.

Hydromedusa tectifera, P. hilarii e T. dorbigni são encontradas em cursos de água urbanos poluídos (e.g. arroio Dilúvio, canal da Mauá, canal da Pintada, todos em Porto Alegre), bem como ambientes que recebem despejo de agrotóxicos. No entanto, não existem estudos sobre o impacto da poluição à sobrevivência dessas espécies nesses locais (C. S. Bujes, obs. pess.). FAGUNDES (2007) sugeriu que T. dorbigni pode ser prejudicada em virtude dos ambientes ocupados em áreas antropizadas, principalmente naqueles que recebem esgotos domésticos e industriais, porém são necessários estudos investigativos neste âmbito.

O impacto negativo das atividades agrícolas sobre extensas áreas de desova às margens dos corpos de água no extremo sul do Rio Grande do Sul (BAGER, 2003), também pode ser constatado na região do baixo Jacuí (C. S. Bujes, obs. pess.).

Os ovos e os juvenis de T. dorbigni sofrem intensa pressão de captura visando suprir o mercado de animais de estimação (FAGUNDES, 2007). Na região do baixo Jacuí há consumo esporádico de indivíduos de $P$. hilarii e $T$. dorbigni na alimentação humana, em forma de carne e ovos (C. S. Bujes, obs. pess.); muitos exemplares destas espécies, na maioria filhotes, foram distribuídos em vários estados brasileiros através de tráfico ou comércio legal (Bujes \& Verrastro, 2008). Filhotes de A. spixii, com sua coloração preta e vermelha atrativa, são vendidos esporadicamente em rodovias gaúchas e alguns exemplares de $H$. tectifera já foram resgatados e/ou entregues à equipe do Projeto Chelonia (organização nãogovernamental com a finalidade de dar suporte às pesquisas que visem à biologia, manejo e conservação de anfíbios e répteis no Rio Grande do Sul), após viverem em aquários como animais de estimação (C. S. Bujes, obs. pess.).

Medidas efetivas à conservação. No Rio Grande do Sul muitas espécies de quelônios ocorrem no interior e no entorno de unidades de conservação e parques urbanos, tais como Estação Ecológica do Taim, Parque Nacional da Lagoa do Peixe e Área de Proteção Ambiental da Lagoa Verde, Parque Estadual de Itapuã, Parque Natural Municipal Saint-Hilaire, Parque Moinhos de Vento, Reserva Biológica do Lami e Jardim Botânico de Porto Alegre (C. S. Bujes, obs. pess.), e ainda na região da Área de Proteção Ambiental Delta do Jacuí (BuJES \& Verrastro, 2008), o que torna desnecessário, no momento, a implementação de unidades de conservação para a conservação dessas espécies. Nesse caso, devese incentivar o cumprimento das leis que determinam a fiscalização destas áreas.

Medidas propostas à conservação. No que se refere a T. dorbigni, se faz necessário: (1) conhecer o mecanismo de seleção sexual; (2) analisar a idade/tamanho com que a maturidade sexual é atingida; (3) avaliar o impacto ambiental de criações clandestinas (coleta de ovos e produção de filhotes visando o comércio de animais de estimação); (4) analisar a composição genética das populações naturais; (5) avaliar o impacto da soltura de filhotes provenientes do tráfico (apreensões realizadas em todo o país) sobre os ecossistemas lagunares do sul do Brasil.

Para A. spixii, H. tectifera e principalmente $P$. geoffroanus e $P$. williamsi, espécies menos conhecidas no âmbito do Rio Grande do Sul, é necessário: (1) 
desenvolver estudos aprofundados, em ambientes preservados e naqueles alterados pelo homem, sobre a biologia, estrutura populacional, densidade e abundância, reprodução e genética; (2) avaliar as consequências de impactos negativos sobre as populações naturais.

Reprodução em cativeiro. Não existem atividades no Rio Grande do Sul, e tampouco projetos que visem avaliar a reprodução das espécies de quelônios em cativeiro.

Investigações atuais. O Projeto Chelonia, desde 2009, vem desenvolvendo estudos ecológicos (estrutura populacional, abundância, biomassa, razão sexual), morfológicos (biométricos, dimorfismo sexual em tamanho do corpo) e sobre o estado de conservação (pressão humana, ameaças, agressões) em ambientes urbanos e semiurbanizados de Porto Alegre (parques municipais e região do Delta do Jacuí), e eventuais registros de ocorrências nas demais regiões. Esses estudos envolvem A. spixii, H. tectifera, P. hilarii e T. dorbigni, bem como a avaliação dos impactos causados pela T. scripta elegans, espécie introduzida no Rio Grande do Sul (Bujes, 2010). Os quelônios são utilizados como ferramentas nas atividades de sensibilização e educação ambiental. Especial atenção está sendo dada ao comportamento reprodutivo, predação, utilização pela população humana e dispersão de $P$. hilarii e $T$. dorbigni, nas lagoas no município de Tapes.

Agradecimentos. Ao apoio logístico do Laboratório de Herpetologia, Departamento de Zoologia, Instituto de Biociências e ao Programa de Pós-Graduação em Biologia Animal, Universidade Federal do Rio Grande do Sul e a ONG Projeto Chelonia. Aos colegas Dr. Franco Leandro Souza e Dr. Flávio de Barros Molina, que muito contribuíram com sugestões, críticas e revisão deste manuscrito.

\section{REFERÊNCIAS BIBLIOGRÁFICAS}

BAGER, A. 1997. Aspectos da dinâmica reprodutiva de Phrynops hilarii (Duméril \& Bibron, 1835) (Testudines, Chelidae) no sul do Rio Grande do Sul. 110p. Dissertação de Mestrado. Universidade Federal do Rio Grande do Sul, Porto Alegre. Brasil.

2003. Aspectos da biologia e ecologia da tartaruga tigre d'água, Trachemys dorbigni (Testudines, Emydidae) no extremo sul do Rio Grande do Sul - Brasil. 100p. Tese de Doutorado. Universidade Federal do Rio Grande do Sul, Porto Alegre.

Bager, A.; Fagundes, C. K. \& Piedras, S. R. N. 2007a. Trachemys dorbigni (Brazilian Slider). Hatchling overwintering. Herpetological Review 38(3):335-336.

Bager, A.; Freitas, T. R. O. \& Krause, L. 2007b. Nesting ecology of a population of Trachemys dorbigni (Emydidae) in Southern Brazil. Herpetologica 63(1):56-65.

BARCo, D. M. \& Larriera, J. A. 1991. Sobre la validez de las subespecies de Trachemys dorbigni y su distribución geográfica (Reptilia, Chelonia, Emydidae). Revista de la Asociación de Ciencias Naturales del Litoral 22(2):11-17.

Bencke, G. A.; Jardim, M. M. A.; Borges-Martins, M. \& Zank, C. 2009. Composição e padrões de distribuição da fauna de tetrápodes recentes do Rio Grande do Sul, Brasil. In: Ribeiro, A. M.; Bauermann, S. G. \& Scherer, C. S. eds. Quaternário do Rio Grande do Sul, Integrando Conhecimentos. Porto Alegre, Monografias da Sociedade Brasileira de Paleontologia, SBP. p.123-142.

Benton, M. J. 1997. Vertebrate Palaeontology. 2 ed. London, Chapman \& Hall. 452p.
BÉRnILs, R. S. 2010. Brazilian reptiles - List of species Sociedade Brasileira de Herpetologia. Disponível em: <http:// www.sbherpetologia.org.br/>. Acesso em 28.08.2010.

Bertonatti, C. 1994. Lista propuesta de anfibios y reptiles amenazados de extinción. Asociación Herpetologica Argentina. Cuadernos de Herpetología 8(1):164-171.

Brandão, R. A.; Zerbini, G. J.; Sebben, A. \& Molina, F. B. 2002 Notes on distribution and habitats of Acanthochelys spixii and Phrynops vanderhaegei (Testudines, Chelidae) in Central Brazil. Boletín de la Asociación Herpetológica Española 13(1-2):11-15.

Bujes, C. S. 1998. Atividade de nidificação de Phrynops hilari (Testudines, Chelidae) na Reserva Biológica do Lami, Rio Grande do Sul, Brasil. Revista Brasileira de Zoologia 15(4):921-928.

2008. Biologia e conservação de quelônios no delta do Rio Jacuí - RS: aspectos da história natural de espécies em ambientes alterados pelo homem. 255p. Tese de doutorado. Universidade Federal do Rio Grande do Sul. Porto Alegre.

2010. Chelonia Project - Study group for freshwater turtle conservation and biology in Southern Brazil: introduction of Trachemys scripta elegans in the Jacuí Delta. Turtle and Tortoise Newsletter 15:5-8.

Bujes, C. S.; Ely, I. \& Verrastro, L. 2007. Trachemys dorbigni (Brazilian Slider). Diet. Herpetological Review 38(3):335.

Bujes, C. S. \& Verrastro, L. 2007. Supernumerary epidermal shields and carapace variation in Orbigny's Slider Turtles, Trachemys dorbigni (Testudines, Emydidae). Revista Brasileira de Zoologia 24(3):666-672

2008. Quelônios do delta do Rio Jacuí, RS, Brasil: uso de hábitats e conservação. Natureza e Conservação 6(2):47-60 2009. Nest temperature, incubation time, hatching, and emergence in the Hilaire's Side-necked Turtle (Phrynops hilarii). Herpetological Conservation and Biology 4(3):306-312.

Buskirk, J. R. 1989. Field observations on Phrynops williamsi and other Uruguayan chelonians. Vivarium 1(4):8-11.

CABrera, M. R. 1998. Las tortugas continentales de Sudamérica Austral. Córdoba, BR Cópias. 108p.

Cielusinsky, L. B.; Budin, M. \& Breyer, E. D. H. 2008. Padrões comparativos referentes à Phrynops williamsi e Hydromedusa tectifera nos municípios de União da Vitória (PR) e Porto União (SC). Ensino e Pesquisa 1(5):112-121.

ERnst, C. H. 1990. Systematics, taxonomy, variation, and geographic distribution of the Slider Turtle. In: GibBons, J. W. ed. Life History and Ecology of the Slider Turtle. Washington, Smithsonian Institution. p.57-67.

Ernst, C. H.; Altenburg, R. G. M. \& Barbour, R. W. 1989 Turtles of the World. ETI, World Biodiversity Database. Disponível em: 〈http://nlbif.eti.uva.nl/bis/turtles.php〉. Acesso em 08.2010.

Fáchin-Terán, A.; Vogt, R. C. \& Soares, M. F. G. S. 1994. Alimentación de tres especies de tortugas Chelidae en Costa Marques, Rondonia, Brasil. Boletin de Lima XVI(9196):409-416.

Fagundes, C. K. 2007. Dinâmica populacional de Trachemys dorbigni (Testudines, Emydidae) em ambiente antrópico em Pelotas, RS. 82p. Dissertação de Mestrado. Universidade Federal de Santa Maria, Santa Maria.

FAgundes, C. K. \& BAger, A. 2007. Ecologia reprodutiva de Hydromedusa tectifera no sul do Brasil. Biota Neotropica 7(2):179-184.

Ferronato, B. O.; Marques, T. S.; Souza, F. L.; Verdade, L. M. \& Matushuma, E. R. 2009. Oral bacterial microbiota and traumatic injuries of free ranging Phrynops geoffroanus (Testudines, Chelidae) in southeastern Brazil. Phyllomedusa 8(1):19-25.

Freiberg, M. A. 1969. Una nueva subespecie de Pseudemys dorbigni (Duméril et Bibron) (Reptilia, Chelonia, Emydidae). Physis 28(77):299-314

FritZ, U. \& HaVAS, P. 2007. Checklist of chelonians of the world Vertebrate Zoology 57(2):149-368.

GaffNey, E. S. \& MeEKer, L. J. 1983. Skull morphology of the oldest turtles: preliminary description of Proganochelys quenstedti. Journal of Vertebrate Paleontology 3:25-28. 
Gaffney, E. S. \& Meylan, P. A. 1988. A phylogeny of turtles. In: Benton, M. D. ed. The phylogeny and classification of tetrapods: amphibians, reptiles, birds. Oxford, Claredon. v. 1 , p.157-219.

Gaffney, E. S.; Meylan P. A. \& Wyss, A. R. 1991. A computer assisted analysis of the relationships of the higher categories of turtles. Cladistics 7:313-335.

Ghizoni-Jr., I. R. \& Graipel, M. E. 2005. Capturas acidentais de vertebrados em estudos com pequenos mamíferos em Santa Catarina, sul do Brasil. Biotemas 18(1):163-180.

Gibbons, J. W.; Scott, E. D.; Ryan, T. J.; Buhlmann, K. A.; Tuberville, T. D.; Metts, B. S.; Geene, J. L.; Mills, T.; Leiden, Y.; Poppy, S. \& Winne, C. T. 2000. The global decline of reptiles, déjà vu amphibians. BioScience 50:653-666.

Gonçalves, F. A.; Cechin, S. Z. \& Bager, A. 2007. Predação de ninhos de Trachemys dorbigni (Duméril \& Bibron) (Testudines, Emydidae) no extremo sul do Brasil. Revista Brasileira de Zoologia 24(4):1063-1070.

Hahn, A. T. 2005. Análise da dieta de Trachemys dorbigni (Duméril \& Bibron, 1835) no sul do Rio Grande do Sul, Brasil (Testudines, Emydidae). 53p. Dissertação de Mestrado. Universidade Federal do Rio Grande do Sul, Porto Alegre.

Hickman, C. P.; Roberts, L. \& Larson, A. 2004. Princípios Integrados de Zoologia. 11 ed. Rio de Janeiro, Guanabara Koogan. 872p.

IUCN (International Union for Conservation of Nature). 2010 IUCN Red List of Threatened Species. Disponível em: <http://www.iucnredlist.org> Acesso em: 28.08.2010.

Iverson, J. B. 1992. A revised checklist with distribution maps of the turtles of the world. Richmond, Privately printed. 363p.

JoHN, L. 2003. Tartarugas a caminho da extinção. In: Revista Ciência e Meio Ambiente, edição de 15 de maio de 2003, Jornal O Estado de São Paulo.

Krause, L.; Gomes, N. \& Leyser, K. L. 1982. Observações sobre a nidificação e desenvolvimento de Chrysemys dorbigni (Duméril \& Bibron, 1835) (Testudines, Emydidae) na Estação Ecológica do Taim, Rio Grande do Sul. Revista Brasileira de Zoologia 1(1):79-90.

LeE, M. S. Y. 1996. Correlated progression and the origin of turtles. Nature 379:812-815.

1997. Pareiasaur phylogeny and the origin of turtles. Zoological Journal of the Linnean Society 120:197-280.

Lema, T. 1994. Lista comentada dos répteis ocorrentes no Rio Grande do Sul, Brasil. Museu de Ciências da PUCRS, Série Zoologia, 7:41-150.

2002. Os répteis do Rio Grande do Sul: atuais e fósseis - biogeografia - ofidismo. Porto Alegre, EDIPUCRS. 264p.

Lema, T. \& Ferreira, M. T. S. 1990. Contribuição ao conhecimento dos Testudines do Rio Grande do Sul (Brasil) - Lista sistemática comentada (Reptilia). Acta Biologica Leopoldensia 12(1):125-164.

Li, C.; Wu, X.-C.; Rieppel, O.; Wang, L.-T. \& Zhao, L.-J. 2008. An ancestral turtle from the Late Triassic of southwestern China. Nature 456:497-501.

Lyson, T. R.; Bever, G. S.; Bhullar, B. A. S.; Joyce, W. G. \& Gauthier, J. A. 2010. Transitional fossils and the origin of turtles. Biology Letters. Disponível em: <http:// rsbl.royalsocietypublishing.org/content/early/2010/06/03/ rsbl.2010.0371.full>. Acesso em: 25.11.2010.

Miorando, P. S. 2006. Ritmo de atividade diário e sazonal de Acanthochelys spixii (Duméril \& Bibron, 1835) (Testudines, Chelidae) em uma área de banhados temporários no Parque Estadual de Itapeva, Torres RS. 37p. Dissertação de Bacharelado. Universidade Federal do Rio Grande do Sul, Porto Alegre.

Mitchell, J. C. \& Klemens, M. W. 2000. Primary and secondary effects of habitat alteration. In: Klemens, M. W. ed. Turtle Conservation. Washington, Smithsonian Institution. p.5-32.

MolinA, F. B. 1996. Mating behavior of captive Geoffroy's sidenecked turtles, Phrynops geoffroanus (Testudines, Chelidae). Herpetological Natural History 4(2):155-160.

Pereira, F. E. \& Diefenbach, C. O. 2001. Growth in Trachemys dorbigni (Testudines, Emydidae). Biociências 9(1):21-31.
Peres, L. C. N. 2010. Caracterização demográfica de Phrynops hilarii (Testudines, Chelidae) em um ambiente urbano de Porto Alegre, RS, Brasil. 37p. Dissertação de Mestrado. Universidade do Vale do Rio dos Sinos, São Leopoldo.

Pinã, C. I.; Lance, V. A.; Ferronato, B. O.; Guardia, I.; Marques, T. S. \& Verdade, L. M. 2009. Heavy metal contamination in Phrynops geoffroanus (Schweigger, 1812) (Testudines: Chelidae) in a River Basin, São Paulo, Brazil. Bulletin of Environmental Contamination and Toxicology 83:771-775.

Pough, F. H.; Heiser, J. B \& McFarlan, W. N. 1996. Vertebrate Life. New York, Prentice Hall. 752p.

Pritchard, P. C. H. 1979. Taxonomy, evolution, and zoogeography. In: Harless, M. \& Morlock, H. eds. Turtles perspectives and research. New York, John Wiley. p.1-42.

Pritchard, P. C. H. \& Trebbau, P. 1984. The turtles of Venezuela. New York, SSAR. 403p.

Rhodin, A. G. J. \& Mittermeier, R. A. 1983. Description of Phrynops williamsi, a new species of Chelid turtle of the South American P. geoffroanus complex. In: Rhodin, A. \& MiYatA, K. eds. Advances in Herpetology and Evolutionary Biology. Essais in Honor of E. E. Williams. Cambridge, Museum of Comparative Zoology. p.58-73.

Rhodin, A. G. J.; Rocha-e-Silva, R. \& Mittermeier, R. A. 1984 Distribution of the South American chelid turtles Platemys radiolata and P. spixii. Copeia 1984:780-786.

Ribas, E. R. \& Monteiro Filho, E. L. A. 2002. Distribuição e hábitat das tartarugas de água doce (Testudines, Chelidae) do Estado do Paraná, Brasil. Biociências 10:15-32.

Rocha, C. F. D.; Bergallo, H. G.; Pombal-Júnior, J. P.; Geise, L.; Van Sluys, M.; Fernandes, R. \& Caramaschi, U. 2004. Fauna de anfíbios, répteis e mamíferos do Estado do Rio de Janeiro, Sudeste do Brasil. Publicações Avulsas do Museu Nacional 104: $1-24$

Romer, A. S. 1966. Vertebrate Paleontology. 3. ed. Chicago, Chicago University. 476p.

Rueda-Almonacid, J. V.; Carr, J. L.; MitTermeier, R. A.; RodriguezMahecha, J. V.; Mast, R. B.; Vogt, R. C.; Rhodin, A. G. J.; OssaVelasquez, J.; Rueda, J. N. \& Mittermeier, C. G. 2007. Las tortugas e los crocodilianos de los países andinos del Trópico. Bogotá, Conservación Internacional. $537 \mathrm{p}$.

Schneider, L.; Ferrara, C. R. \& Vogt, R. C. 2009. Phrynops geoffroanus (Geoffroy's side necked turtle): nest predation. Herpetological Review 40(4):436.

Shaffer, H. B.; Meylan, P. \& McKnight, M. L. 1997. Tests of turtle phylogeny: molecular, morphological, and paleontological approaches. Systematic Biology 46:235268

Sousa, B. M. \& Novelli, I. A. 2009. Reptilia, Testudines, Chelidae: Hydromedusa tectifera, distribution extension in Brazil. Checklist 5(3):396-398.

SouZA, F. L. 1999. Ecologia do cágado Phrynops geoffroanus (Schweigger, 1812) em ambiente urbano poluído (Reptilia, Testudines, Chelidae). 52 p. Tese de Doutorado. Universidade Estadual Paulista "Júlio Mesquita Filho", Rio Claro.

2004. Uma revisão sobre padrões de atividades reprodutivas e alimentação de cágados brasileiros (Testudines, Chelidae). Phyllomedusa 3(1):15-27.

Souza, F. L. \& AвE, A. 2000. Feeding ecology, density and biomass of the freshwater turtle Phrynops geoffroanus inhabiting a polluted urban river in southeastern Brazil. Journal of Zoology 252:437-446.

2001. Population structure and reproductive aspects of the freshwater turtle Phrynops geoffroanus, inhabiting an urban river in southeastern Brazil. Studies on Neotropical Fauna and Environment 36(1):57-62.

Souza, F. L.; Giraldelli, G. R. \& Martins, T. A. 2006. Reproductive aspects of Brazilian Side-Necked-Turtles (Chelidae). Boletín de la Asociación Herpetológica Española 17(1):28-34.

SouzA, F. L. \& Martins, F. I. 2009. Hydromedusa maximiliani (Mikan 1825) - Maximilian's Snake-Necked Turtle, Brazilian Snake-Necked Turtle. In: Rhodin, A. G. J.; Pritchard, P. C. H.; VAn Dijk, P. P.; Saumure, R. A.; Buhlmann, K. A.; Iverson, J. B. \& Mittermeier, R. A. eds. Conservation biology of Freshwater Turtles and Tortoises: a compilation project of the IUCN/ 
SSC Tortoise and Freshwater Turtle Specialist Group. Chelonian Research Monographs. Disponível em: < http:/ /www.iucn-tftsg.org/cbftt/>. Acesso em: 25.11.2010.

Souza, F. L.; Raizer, J.; Costa, H. T. M. \& Martinez, F. I. 2008. Dispersal of Phrynops geoffroanus (Chelidae) in an urban river in Central Brazil. Chelonian Conservation and Biology 7(2): 257-261,

Torres, D. F.; Oliveira, E. S.; Alves, R. R. N. \& Vasconcellos, A. 2009. Etnobotânica e etnozoologia em unidades de conservação: uso da biodiversidade na APA de Genipabu, Rio Grande do Norte, Brasil. Interciencia 34(9):623-629.
Tortato, M. A. 2007. Contribuição ao conhecimento de Phrynops hilarii (Duméril \& Bibron, 1835) (Testudines, Chelidae) em área de restinga no estado de Santa Catarina, Sul do Brasil. Biotemas 20(1):119-122.

Vanzolini, P. E. 1997. A note on the reproduction of Trachemys dorbigni (Testudines, Emydidae). Revista Brasileira de Zoologia 57(2):165-175.

Vieira, E. F. 1984. Rio Grande do Sul: geografia física e vegetação. Porto Alegre, Sagra. 184p.

Vogt, R. C. 2008. Tartarugas da Amazônia. Lima, Gráfica Biblos. 104p. 